\title{
Utilizing Brachionus biodiversity in marine finfish larviculture
}

\author{
Terry W. Snell • Rachel K. Johnston • Amelia B. Matthews
}

Received: 5 July 2018/Revised: 17 September 2018/Accepted: 18 September 2018/Published online: 9 October 2018

(C) The Author(s) 2018

\begin{abstract}
Mouth gape sizes of marine finfish larvae determine the size of rotifer prey that can be ingested, so providing appropriate size rotifers controls the success of larval rearing. It is difficult for hatcheries to maintain pure cultures of multiple rotifer species by long-term serial dilution without cross-contamination. In this paper, we describe a technique for utilizing multiple rotifer species in larviculture that uses rotifer diapausing eggs as inocula, enabling hatcheries to supply larval predators with optimally sized rotifers. Biodiversity in the Brachionus plicatilis species complex is extensive, including considerable variation in body size. In this paper, we show that large quantities of diapausing eggs can be produced from many Brachionus species. Using the full range of body size diversity from seven Brachionus species, we can produce adult female rotifers with mean body lengths as small as $137 \mu \mathrm{M}$, or as large as $305 \mu \mathrm{M}$, and neonate females with body lengths ranging from 103 to $206 \mu \mathrm{M}$. The length of diapausing eggs for small Brachionus species averaged $100 \mu \mathrm{M}$, and $166 \mu \mathrm{M}$ for large species. Diapausing egg production varied by
\end{abstract}

Guest editors: Steven A. J. Declerck, Diego Fontaneto, Rick Hochberg \& Terry W. Snell / Crossing Disciplinary Borders in Rotifer Research

T. W. Snell ( $\square)$ · R. K. Johnston · A. B. Matthews School of Biological Sciences, Georgia Institute of Technology, Atlanta, GA 30332-0230, USA

e-mail: terry.snell@biosci.gatech.edu
3.6 fold among 14 strains. Using diapausing eggs of the very small rotifer Proales similis $(88 \mu \mathrm{M})$ to inoculate mass cultures also is described.

Keywords Rotifers - Aquaculture - Fish larvae · Biodiversity $\cdot$ Resting eggs $\cdot$ Mass culture $\cdot$ Body size

\section{Introduction}

Over the last 20 years, biologists have developed a deeper understanding of the species diversity in the taxon Brachionus plicatilis Muller, 1786. Brachionus plicatilis was classified as a single species until 1995 when a second species, B. rotundiformis Tschugunoff, 1921, was considered valid (Segers, 1995). Since then, it was recognized that $B$. plicatilis is actually a cryptic species complex composed of at least 15 species (Mills et al., 2017; Serra \& Fontaneto, 2017). This analysis is the synthesis of many authors working over a few decades and is based on morphological, ecological, and gene sequence analyses. If this biodiversity is to be useful in any application, we need to develop means for its collection, storage, and distribution. The life cycle of monogonont rotifers provides a mechanism to achieve this with diapausing eggs. They are able to withstand desiccation and freezing and remain viable for decades in a laboratory (Pourriot \& Snell, 1983; Schroder, 2005; García-Roger et al., 2006). 
The storage and distribution of this rotifer biodiversity present an opportunity for aquaculture, which is still heavily reliant on live rotifer feeds for the larval rearing of many marine finfish (Hagiwara et al., 2001; Lubzens et al., 2001; Conceicao et al., 2010; Hagiwara et al., 2017). Three morphotypes were recognized early in the history of rotifers in aquaculture (Fu et al., 1991). These were called "L", "S," and "M" morphotypes and corresponded to large, small, and medium body sizes, respectively. These morphotypes are utilized for larviculture of fish with corresponding mouth gape sizes (Hagiwara et al., 2001; Kotani, 2017). It was long understood that rotifer body size is primarily one of genetically determined trait, with only small influences of environmental conditions (Yufera, 1982; Snell \& Carrillo, 1984). Snell and Carillo (1984) reported that Brachionus body length could be changed by diet, temperature, or salinity manipulations by only 15,12 , or $11 \%$, respectively. In contrast, they showed that neonate rotifers are about $85 \%$ smaller than fully grown adults, and increase in size post-hatch is primarily by cytoplasm synthesis rather than cell division. Kotani et al. (2006) demonstrated that it is possible to make crosses between a Japanese and German strain to produce hybrids. The F1 hybrids had 19\% higher reproductive rates and an intermediate body length $(276 \mu \mathrm{m})$ between the two parental strains.

Using appropriate size rotifer strains for marine finfish larviculture to a large extent determines its success (Hagiwara et al., 2001; Lubzens et al., 2001; Kotani, 2017). For example, Hagiwara et al. (2007) reported rearing larvae of the threeline grunt, Parapristipoma trilineatum Thunberg, 15 days post-hatch on the rotifer $B$. rotundiformis (lorica length, 90-210 $\mu \mathrm{m}$ ). These larvae grew much better during the first 7 days than larvae fed $B$. plicatilis (160-320 $\mu \mathrm{m})$ exclusively. However, the larvae grew better when fed the larger B. plicatilis after day 7 . The key to being able to apply such a feeding regime in hatcheries is maintaining mass cultures of rotifer species of different sizes (Hagiwara et al., 2007). Those authors also surveyed 70 genetically distinct Brachionus strains and found adult female body lengths ranged from 170 to $320 \mu \mathrm{m}$ when cultured under standard conditions of $25^{\circ} \mathrm{C}$ and 22 psu salinity. Body size grew up to $20 \%$ larger when cultured at low temperatures $\left(10-15^{\circ} \mathrm{C}\right)$ or low salinity $(10-15 \mathrm{psu})$. This result was corroborated by Walczynska and Serra
(2014) who showed that adult body volume was smaller by $19 \%$ at $27.5^{\circ}$ compared to that at $17.5^{\circ} \mathrm{C}$ in B. plicatilis. Hagiwara et al. (2007) found that a diet of yeast also produced rotifers $14-17 \%$ smaller than a diet of the alga Nannochloropsis oculata Droop 1955. Hagiwara et al. maintained about 100 Brachionus strains in their lab by serial dilution culture. They reported that only about 20 strains retain the ability to reproduce sexually in their culture conditions. This observation illustrates the common tendency of Brachionus cultures to rapidly lose the ability for sexual reproduction after several months in laboratory culture (Serra \& Snell, 2009).

A variety of Brachionus species currently are utilized in European hatcheries. These include $B$. plicatilis s.s, B. asplanchnoidis Charin, 1947, B. koreanus and B. 'Nevada.' Papakostas et al. 2006; Kostopoulou et al. 2009. Brachionus 'Nevada' is genetically distinct, but it is an as yet unnamed species in the B. plicatilis species complex (Mills et al., 2017). One likely reason for deploying different Brachionus species in different European hatcheries is that they undergo markedly different optimal growing conditions. This is not surprising when considering environmental conditions over the geographic range from Norway to Greece. Each fish hatchery has a unique set of environmental conditions and style of operation. By selecting among the various Brachionus species for growth under the specific conditions of the hatchery, rotifer production and culture stability can be optimized. Choosing the best among several Brachionus species makes it more likely that hatcheries will be able to closely match their rotifer production to their growing conditions and the needs of their larval predator (Conceicao et al., 2010; Kim et al., 2017; Kotani, 2017).

A variety of ecological differences among the Brachionus species have been documented. These include species-specific salinity, temperature, and diet optima, and traits that affect mass culture performance like tolerance of ammonia, starvation, and hypoxia. For example, B. plicatilis s.s. grows better at lower temperatures and salinities than $B$. manjavacas Fontaneto et al. 2007, B. ibericus Ciros-Perez et al. 2001 and $B$. rotundiformis. In comparison, B. ibericus is better adapted to low salinity and high temperature, whereas $B$. rotundiformis performs better at high salinity and high temperature (Gabaldon et al., 2017). These ecological preferences can be exploited in 
aquaculture by choosing the rotifer species that is best adapted to local growing conditions.

Despite the advantages of using multiple rotifer species of different sizes in larviculture (Lubzens et al., 2001), it is often difficult for hatcheries to maintain them in separate mass cultures. This is because maintaining pure rotifer cultures by long-term serial dilution is technically difficult even for the most experienced labs. A single error can result in crosscontamination, which typically leads to rapid competitive exclusion of one species (Ortells et al., 2003). Our main objective in this work is to extend the number of Brachionus species for which diapausing eggs are available for aquaculture beyond the two commonly used species: Brachionus plicatilis and $B$. rotundiformis. A secondary objective is to characterize the size of several B. plicatilis complex species, demonstrate their ability to produce diapausing eggs in collectible quantities, confirm their genetic identity, and compare diapausing egg hatching and population growth rates among species. We hypothesize that it is possible to develop a collection of diapausing eggs, which makes a larger fraction of the size variation in the B. plicatilis species complex available to aquaculture. Such a collection of diapausing eggs will enable hatcheries to conveniently use a broader array of Brachionus biodiversity in larval rearing by maintaining several rotifer species as diapausing eggs without cross-contamination. This enables hatcheries to supply their larval predators with optimally sized rotifers during fish larval development, grow rotifer strains best adapted for local environmental conditions, and reduce the time required for upscaling from stock to mass cultures.

\section{Methods}

Rotifer collection

Rotifer strains were obtained from a variety of sources over more than three decades. Once acquired, strains were initially maintained by serial dilution culture as described in the next section. If males and diapausing egg production could not be induced under our lab conditions, these strains were eliminated from the collection. The strains that became permanent members of the collection were gifts from the following researchers: Brachionus manjavacas (Bm) Russian-
Patrick Sorgeloos, University of Ghent; $B$. manjavacas $(\mathrm{Bm})$ Petta, B. rotundiformis $(\mathrm{Br})$ Italy, $B$. plicatilis (Bp) AUPEA006, B. manjavacas (Bm) Gaynor Pond, B. sp. "Almenara" LL1-Lisa Suatoni, Yale University; B. manjavacas (Bm) Manjavacas, $B$. plicatilis (Bp) Poza Sur, B. plicatilis (Bp) SalobrejoManuel Serra, University of Valencia; B. plicatilis (Bp) Tokyo NH1L, B. rotundiformis $(\mathrm{Br})$ Hawaii, B. sp. JPN S-type 2014-Atsushi Hagiwara, Nagasaki University; B. sp. "Nevada"-Stephanie Hampton, Washington State University; B. plicatilis (Bp) China-commercial purchase, Proales similis De Beauchamp 1907-S. Nandini, Universidad Nacional Autónoma de México; B. calyciflorus Pallas 1776 (Bc) Gainesville-personal collection.

\section{Culture conditions}

Rotifer cultures were maintained in 15 psu artificial seawater (ASW, Instant Ocean) and were fed the green alga Tetraselmis suecica (Kylin) Butcher 1959. Tetraselmis suecica was cultured in modified $\mathrm{F}$ medium (Guillard 1983) under constant fluorescent illumination of 2000 lux. For B. rotundiformis HAW, improvements in growth rates and diapausing egg production were observed at higher salinities, so $\mathrm{Br}$ HAW was cultured in 27 psu ASW. As a freshwater species, B. calyciflorus Gainesville was cultured in EPA medium (U.S. Environmental Protection Agency 1985) and was fed the green alga Chlorella kessleri Fott \& Nováková 1969. Chlorella kessleri was cultured in a hydroponic growth media made from FloraMicro and FloraBloom nutrients (General Hydroponics, https://generalhydroponics.com/ floraseries/). For experiments using neonates, rotifers were hatched from diapausing eggs in $5 \mathrm{ml} 15 \mathrm{psu}$ ASW, 27 psu ASW (B. rotundiformis HAW), or EPA (B. calyciflorus Gainesville) under constant fluorescent illumination (2000 lux) at $25^{\circ} \mathrm{C}$. Diapausing egg hatching occurred between 15 and $72 \mathrm{~h}$, depending on the strain.

Diapausing egg production, drying, and storage

To produce diapausing eggs, rotifers were first cultured in a 1-1 flask with 15 psu ASW and $T$. suecica. These flask cultures were started either from neonates hatched from diapausing eggs or from the existing serial dilution cultures. Once the flasks 
reached sufficient density, five to ten 121 bags of $15 \mathrm{psu}$ ASW and around $2 \times 10^{5}$ cells $/ \mathrm{ml} \mathrm{T}$. suecica were inoculated at a density of 400 female rotifers/bag (0.03 rotifers $/ \mathrm{ml}) .121 \mathrm{bag}$ cultures were supplemented periodically with 50 to $100 \mu \mathrm{g} / \mathrm{ml}$ S.parkle commercial rotifer feed (INVE Aquaculture, http:// www.inveaquaculture.com), depending on the density of rotifers.

Samples from each bag were checked daily for rotifer density and diapausing egg production. When diapausing egg production was complete, the bags were drained into buckets where the diapausing eggs settled to the bottom. The top portion of the bucket was carefully decanted off, and the remaining portion was blended to break up any algae clumps. The diapausing eggs were retained on a $53-\mu \mathrm{m}$ mesh filter and rinsed several times to wash away any remaining algae.

Once diapausing eggs were collected, they were rinsed off the filter into a beaker and stored in water at $4^{\circ} \mathrm{C}$ for at least 1 month. This incubation allows the diapausing eggs to complete development and promotes synchronous hatching. After incubation, the eggs were filtered onto $53 \mu \mathrm{m}$ mesh and allowed to air-dry overnight at room temperature. Once dry, the eggs were broken up to get a loose powder by hand and stored in glass vials at $-20^{\circ} \mathrm{C}$. Once dried and stored at $-20^{\circ} \mathrm{C}$, these diapausing eggs are viable for several years. The dry mass of each batch of diapausing eggs produced was recorded to calculate the average production in $\mathrm{mg} / \mathrm{l}$.

To optimize diapausing egg production and recovery, modifications were made for some strains. For $\mathrm{Br}$ HAW, the salinity of culture medium was raised to 27 psu. For Bc Gainesville, rotifers were cultured in EPA and fed C. kessleri or Chlamydomonas reinhardtii P.A.Dangeard 1888. Due to their small size, diapausing eggs from $\mathrm{Bc}$ Gainesville, $\mathrm{Br} \mathrm{HAW}, \mathrm{Br}$ Italy, and B. sp. JPN S-type 2014 were collected using $25 \mu \mathrm{m}$ mesh. Brachionus sp. "Almenara" and B. sp. JPN S-type 2014 carried their diapausing eggs internally, so instead of decanting, the contents of the entire culture were filtered and processed.

The diapausing eggs of $P$. similis are not morphologically distinguishable from their asexual eggs. Consequently, $P$. similis were allowed to naturally deposit their diapausing eggs in microcentrifuge tubes without further concentration.
COI sequencing and bioinformatics

The COI gene sequencing was performed on multiple clones from each Brachionus strain to verify the species identity and purity of each culture. Biomass of several hundred rotifers was collected on $25-53 \mu \mathrm{m}$ mesh depending on the size of the strain, and genomic DNA was extracted using the Qiagen DNeasy Blood and Tissue kit. We employed PCR to amplify the COI gene using universal invertebrate primers LCO1490 (5'-GGTCAACAAATCATAAAGATATTGG-3') and HCO2198 (5'-TAAACTTCAGGGTGACCAAAAAATCA- $3^{\prime}$ ). Thermocycler conditions for amplification were $2 \mathrm{~min}$ at $95^{\circ} \mathrm{C}$ and 40 cycles of $95^{\circ} \mathrm{C}$ for $30 \mathrm{~s}, 45-47^{\circ} \mathrm{C}$ for $90 \mathrm{~s}$, and $72^{\circ} \mathrm{C}$ for $90 \mathrm{~s}$. The PCR product was run on a $1.5 \%$ agarose gel, and bands were extracted using the QIAquick Gel Extraction Kit (Qiagen). Purified COI DNA was sequenced by Eurofins Genomics, and sequences were aligned and edited using CodonCode Aligner (CodonCode Corporation, http://www.codoncode.com/aligner/). Sequences were compared to Brachionus or Proales COI sequences in GenBank using the standard nucleotide BLAST (megablast). Phylogenetic analysis was performed using the Clustal Omega Program (https://www.ebi.ac.uk/Tools/msa/clustalo/). We selected the best COI sequence match from a population isolated from the same geographic location.

\section{Body size and egg measurements}

To compare sizes of different rotifer strains, measurements were taken of the lengths and widths of the lorica of both neonates and adults. Neonates were hatched from diapausing eggs and collected within a few hours of hatching, and ovigerous adult females were collected from established log-phase cultures. Animals were transferred to $0.5 \mathrm{ml} \mathrm{ASW}$, anesthetized with $1 \mathrm{ml}$ club soda, and fixed with 1-20 $\mu \mathrm{l}$ $20 \%$ formalin. Animals were imaged at 200-400 $\times$ depending on their size, using a Zeiss Imager Z1 microscope. Lorica length and width was measured in these images using ImageJ (https:// imagej.nih.gov/ij/). 10 to 15 animals of each age and strain were measured to calculate the average body size. To measure egg size, diapausing eggs were rehydrated in ASW for at least $30 \mathrm{~min}$ and pipetted onto slides. 10 to 15 eggs for each strain were imaged 
at $\times 400$ using the Zeiss Imager Z1. Length and width were measured for each image using ImageJ.

Diapausing egg hatching

To determine the hatching rates of each batch of diapausing eggs, they were first rehydrated with the appropriate media. The Br HAW was rehydrated with 27 psu ASW, Bc Gainesville was rehydrated with EPA, and all other strains were rehydrated with 15 psu ASW. Diapausing eggs were incubated in media at $25^{\circ} \mathrm{C}$ for at least $30 \mathrm{~min}$, and then transferred into 24-well plates. A total of 100-120 eggs were transferred for each strain, with 20 eggs each placed in replicate wells. Eggs were carefully examined for intact, well-formed embryos and membranes, and any eggs that appeared damaged were removed. This typically was less than $10 \%$ of the population. Plates were incubated at $25^{\circ} \mathrm{C}$ under constant fluorescent illumination (2000 lux). Number of animals hatched was scored after 24,48 , and $72 \mathrm{~h}$, and cumulative percent hatching was calculated for each time point. If hatching rate for any strain was below $20 \%$, that strain was repeated with rehydration in $7.5 \mathrm{psu}$ ASW to determine if salinity affected the hatching rate.

Population growth rate estimates

Population growth rate experiments were conducted using neonates hatched from diapausing eggs. For each strain, two neonates were added to each of 8 replicate wells in a 24-well plate. Wells contained $6 \times 10^{5}$ cells $/ \mathrm{ml} \mathrm{T}$. suecica in $1 \mathrm{ml} 15 \mathrm{psu}$ ASW. For Br HAW, wells contained T. suecica in 27 psu ASW, and for Bc Gainesville, wells contained $7 \times 10^{6}$ cells/ $\mathrm{ml}$ C. kessleri in $1 \mathrm{ml}$ EPA. Brachionus sp. JPN S-type 2014 grew better at low algae density, so wells contained only $1 \times 10^{5}$ cells $/ \mathrm{ml} \mathrm{T}$. suecica. Plates were incubated in the dark at $25^{\circ} \mathrm{C}$, and the number of animals in each well was counted at 48 and $72 \mathrm{~h}$. The average population growth rate/day $(r)$ was calculated for each strain at $72 \mathrm{~h}$.

\section{Results}

Diapausing egg production and size

This collection of Brachionus plicatilis species complex geographic isolates contains diapausing eggs of five well-characterized species and three as yet unnamed species (Table 1). Some diapausing eggs (e.g., Brachionus manjavacas "Russian") were obtained more than 35 years ago and preserved dry in a freezer $\left(-20^{\circ} \mathrm{C}\right)$ with periodic hatching. Others were obtained as live cultures and maintained as serial dilution cultures until they could be tested for diapausing egg production. Through the years, we have tested 24 brachionid strains for diapausing egg production under our test conditions. $29 \%$ never produced males or diapausing eggs, and they were dropped from the collection. We were left with 16 strains and species that reproducibly produced enough diapausing eggs so that they could be collected, dried, and stored in a freezer without the need for continuous culturing.

Diapausing eggs of these Brachionus species were all ovoid in shape, without obvious surface sculpturing at $\times 400$ magnification. Diapausing egg lengths ranged from $166 \mu \mathrm{m}$ for $B$. manjavacas Rus to $100 \mu \mathrm{m}$ for $B$. rotundiformis HAW (Table 2). Widths for these species were 114 and $73 \mu \mathrm{m}$, respectively. These measurements enabled us to estimate diapausing egg volume using the equation of Walsh et al. (2017). Mean diapausing egg volume of the $B$. plicatilis/manjavacas species was $9.31 \times 10^{5} \mu^{3}$ compared to 2.83 for $B$. rotundiformis species and 5.43 for B. calyciflorus. The volumes of these Brachionus diapausing eggs are on the small end of the species distribution described by Walsh et al. (2017).

Genetic classification of species and strains

Using an average of 661 (561-717) nucleotides from the COI mitochondrial gene sequence, we were able to classify all geographic populations into species (Table 1). This represented $89-100 \%$ coverage of the gene, with identity ranging from 95 to $100 \%$ for Brachionus species and $83 \%$ for Proales. The Evalues were at or near 0 for all populations, so we have high confidence in the classification of these species.

Of the 16 rotifer strains in this collection, 4 are $B$. manjavacas, 5 are B. plicatilis, 2 are B. rotundiformis 


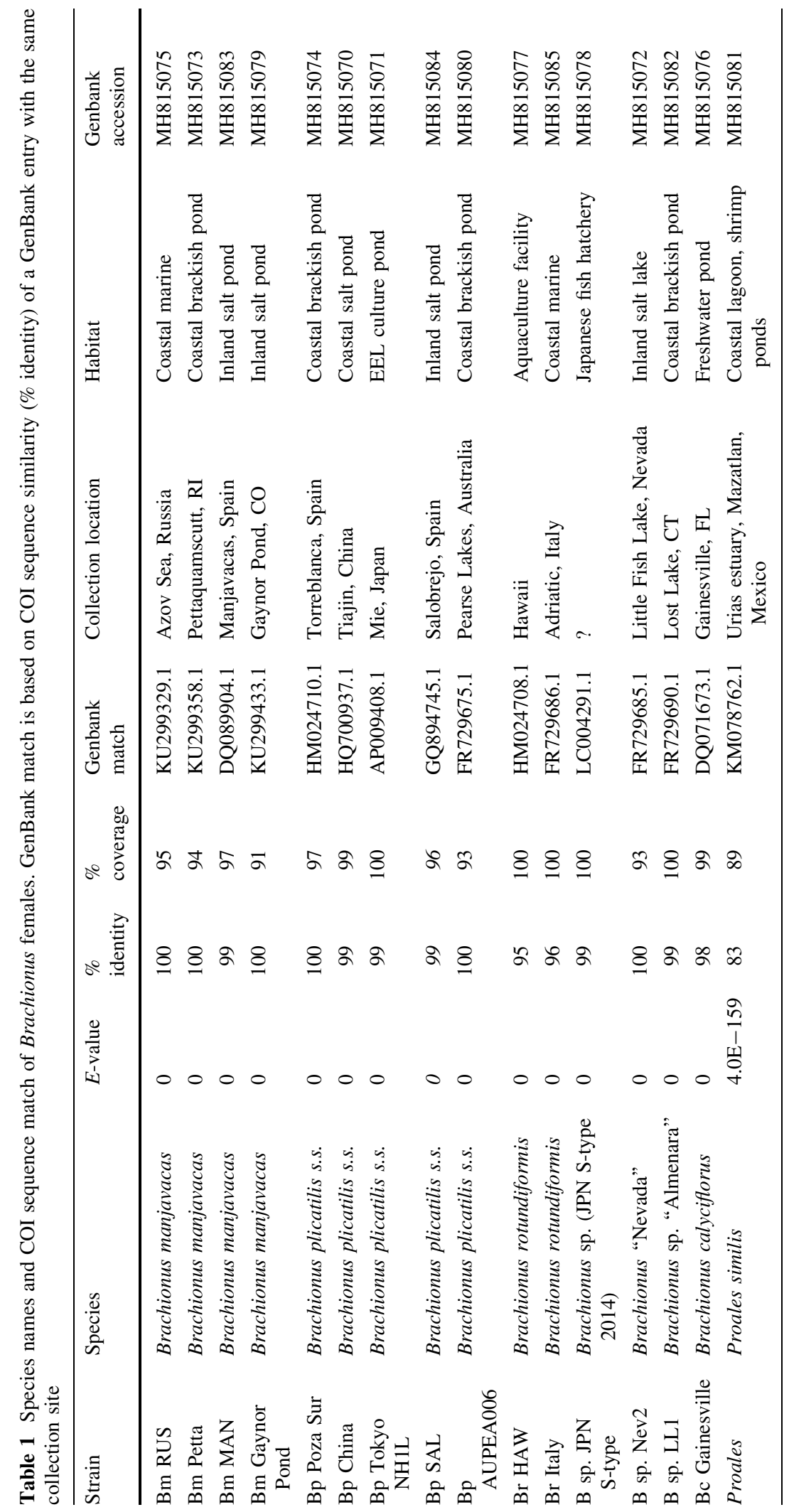


Table 2 Diapausing egg lengths and widths

\begin{tabular}{|c|c|c|c|c|c|c|c|}
\hline \multirow[t]{2}{*}{ Strain } & \multirow[t]{2}{*}{ Species } & \multicolumn{6}{|c|}{ Diapausing eggs } \\
\hline & & Length $(\mu \mathrm{M})$ & SD & $\mathrm{CV}(\%)$ & Width $(\mu \mathrm{M})$ & SD & $\mathrm{CV}(\%)$ \\
\hline Bm RUS & Brachionus manjavacas & 165.68 & 4.51 & 2.72 & 113.53 & 2.67 & 2.35 \\
\hline Bm Petta & Brachionus manjavacas & 155.49 & 9.24 & 5.94 & 115.27 & 2.70 & 2.35 \\
\hline Bm MAN & Brachionus manjavacas & 141.48 & 7.77 & 5.49 & 98.06 & 6.00 & 6.12 \\
\hline Bm Gaynor Pond & Brachionus manjavacas & 147.09 & 5.32 & 3.62 & 109.57 & 2.78 & 2.54 \\
\hline Bp Poza Sur & Brachionus plicatilis s.s. & 142.90 & 1.23 & 0.86 & 95.49 & 4.45 & 4.66 \\
\hline Bp China & Brachionus plicatilis s.s. & 151.13 & 6.71 & 4.44 & 107.07 & 4.61 & 4.30 \\
\hline Bp Tokyo NH1L & Brachionus plicatilis s.s. & 146.68 & 13.96 & 9.51 & 106.43 & 3.38 & 3.17 \\
\hline Bp SAL & Brachionus plicatilis s.s. & 148.18 & 8.82 & 5.95 & 107.27 & 3.51 & 3.27 \\
\hline Bp AUPEA006 & Brachionus plicatilis s.s. & 150.39 & 8.01 & 5.32 & 109.39 & 5.15 & 4.71 \\
\hline Br HAW & Brachionus rotundiformis & 99.79 & 3.27 & 3.28 & 72.60 & 3.38 & 4.66 \\
\hline Br Italy & Brachionus rotundiformis & 104.07 & 6.50 & 6.24 & 75.12 & 5.21 & 6.94 \\
\hline$B$ sp. JPN S-type & Brachionus sp. (JPN S-type 2014) & 113.75 & 3.56 & 3.13 & 80.83 & 1.57 & 1.94 \\
\hline B sp. Nev2 & Brachionus "Nevada" & 155.79 & 7.71 & 4.95 & 104.74 & 4.09 & 3.90 \\
\hline B sp. LL1 & Brachionus sp. “Almenara” & 148.40 & 8.78 & 5.92 & 106.40 & 3.76 & 3.53 \\
\hline Bc Gainesville & Brachionus calyciflorus & 135.58 & 6.67 & 4.92 & 87.43 & 5.17 & 5.91 \\
\hline
\end{tabular}

Bm: Brachionus manjavacas; Bp: Brachionus plicatilis; Br: Brachionus rotundiformis; Bc: Brachionus calyciflorus; RUS: Russian; Petta: Pettaquamscutt; MAN: Manjavacas; SAL: Salobrejo; HAW: Hawaii; JPN: Japan; Nev2: Nevada 2; LL1: Lost Lake 1

and 3 are unnamed Brachionus species. One is a freshwater species (B. calyciflorus) and one is not a brachionid (Proales similis). All of the marine species come from coastal marine habitats, coastal brackish ponds, or inland salt lakes. A few were obtained from an aquaculture facility (e.g., Brachionus rotundiformis HAWaii), but the origin of the natural population is unknown.

Body size measurements

The largest adult females in this collection are $B$. plicatilis species, with a mean length of $261 \mu \mathrm{m}$ and width of $202 \mu \mathrm{m}$ (Table 3). Brachionus manjavacas species averaged about $6 \%$ smaller at $247 \mu \mathrm{m}$ long and $201 \mu \mathrm{m}$ wide. Brachionus rotundiformis species were markedly smaller, averaging $148 \mu \mathrm{m}$ long and $124 \mu \mathrm{m}$ wide. The average length/width ratio for all Brachionus species is 1.26 and the adult/neonate length ratio is 1.39. The largest adult brachionid females were B. plicatilis Tokyo, averaging $304 \mu \mathrm{m}$ in length, whereas the smallest was $B$. rotundiformis Italy at $137 \mu \mathrm{m}$. Proales similis was by far the smallest rotifer measured, with adult females averaging $88 \mu \mathrm{m}$ long and $48 \mu \mathrm{m}$ wide. Examples of the morphologies of a few B. plicatilis species complex females and diapausing eggs are shown in Fig. 1a, b.

Diapausing egg production rate

Under our culture conditions, Brachionus species in the collection produced from 2.5 to $40 \mathrm{mg}$ dry diapausing eggs/l, with a mean of $11.92 \pm 2.67$ (Table 4). Since one mg dry weight equals approximately 2500 diapausing eggs, our production system averaged about 29,800 diapausing eggs/l in a 3-week production cycle. Brachionus plicatilis and B. manjavacas populations produced diapausing eggs at similar rates, and both were often more productive than $B$. rotundiformis species.

Diapausing egg hatching fraction

Dried diapausing eggs produced in our lab began hatching about $24 \mathrm{~h}$ after hydration at $25^{\circ} \mathrm{C}$ in light (Table 5). Some species (Br Italy, Brachionus sp. Nev2, and Br HAW) require longer, initiating hatching after $48 \mathrm{~h}$. Cumulative hatching fractions after 


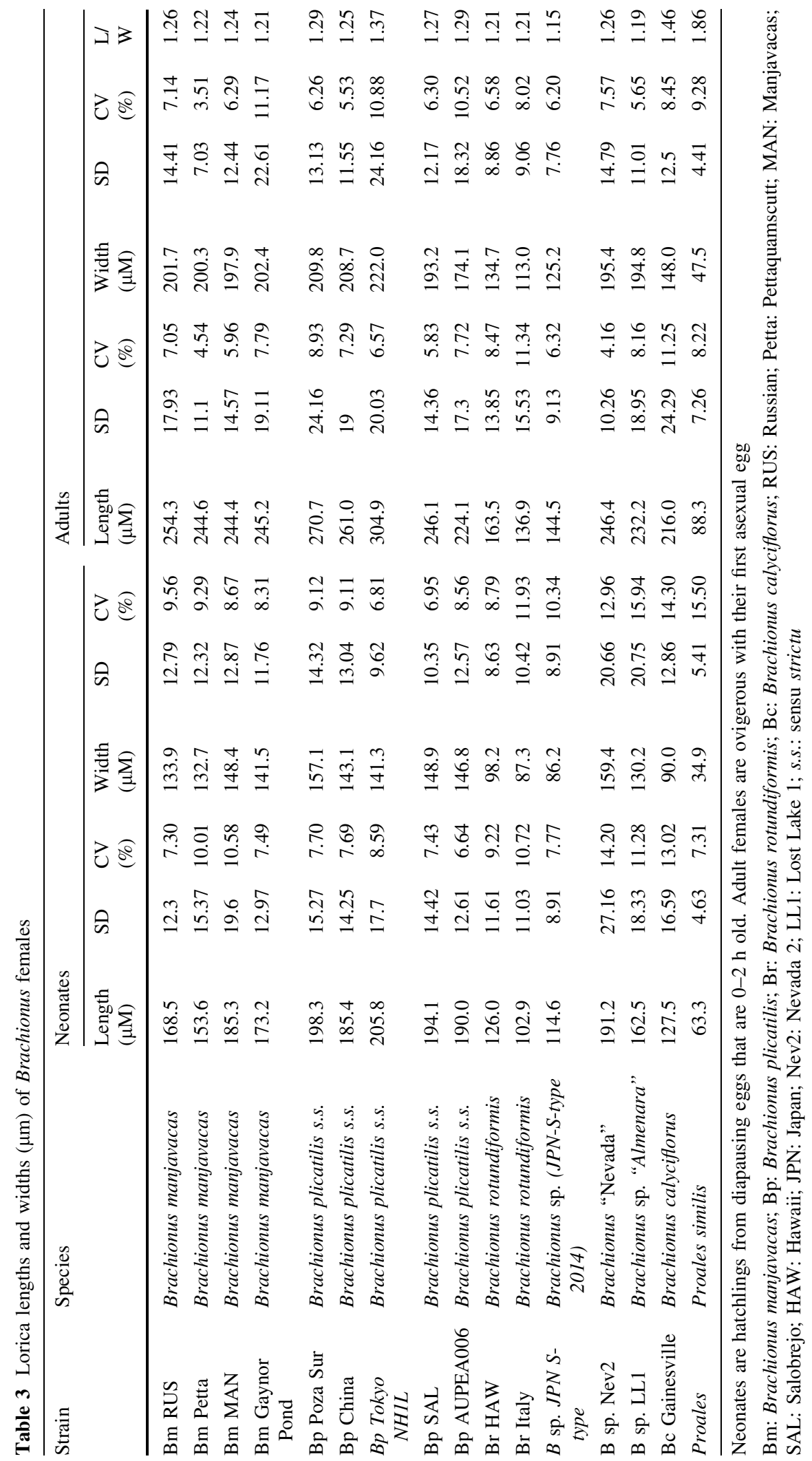


a

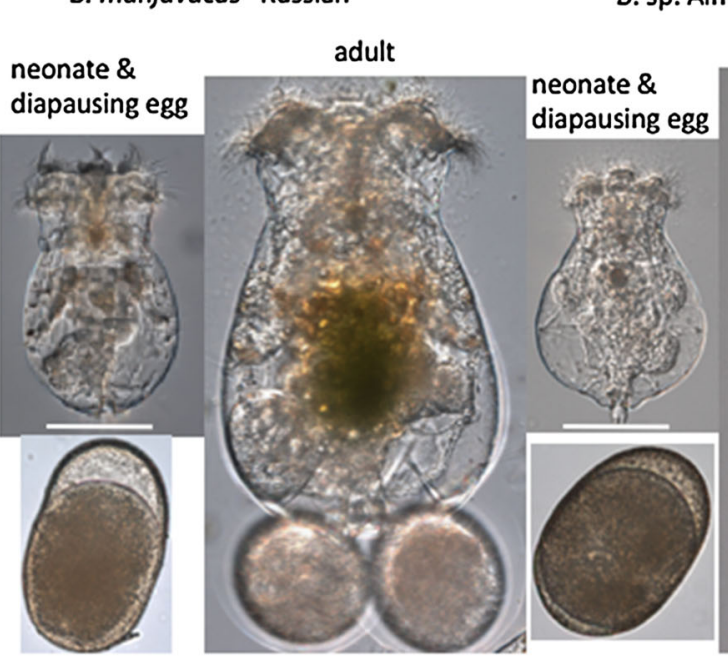

B. sp. Almenara "Lost Lake, CT" adult

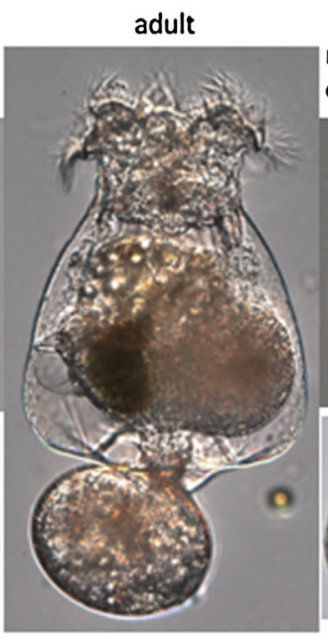

B. rotundiformis "Italy"

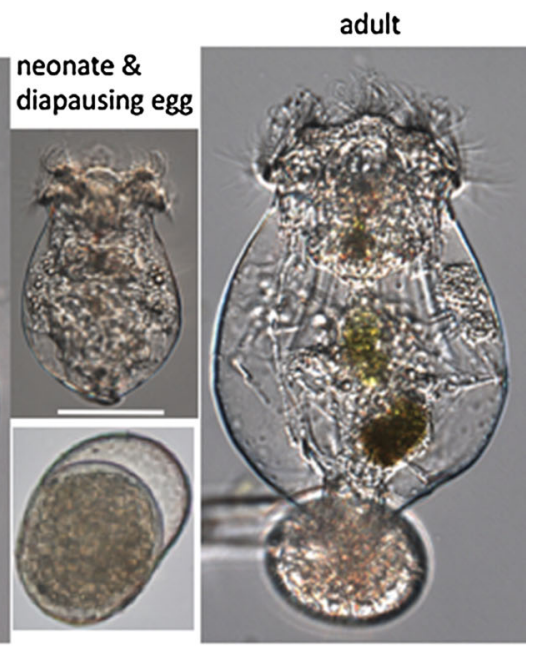

b

\section{B. rotundiformis "Hawaii"}

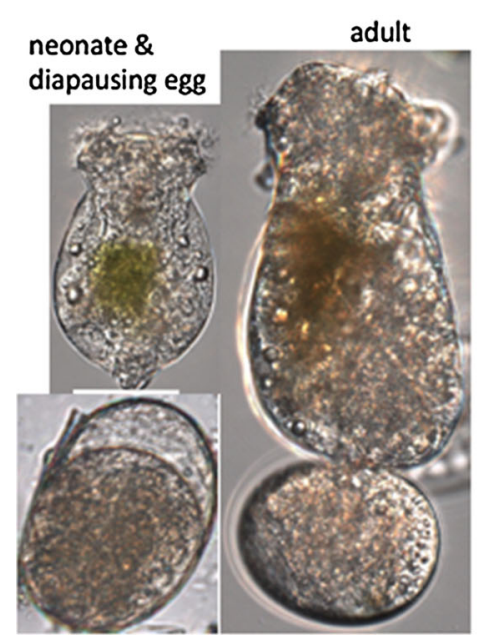

B. plicatilis s.s. "China"

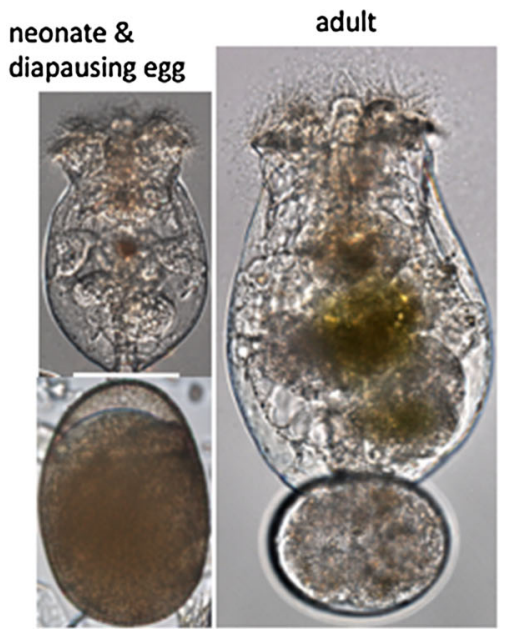

B. manjavacas "Gaynor Pond, USA"

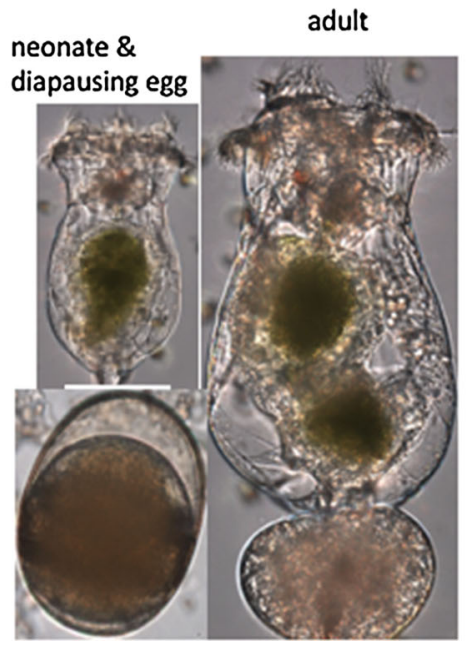

Fig. 1 a, b Exemplary photomicrographs of representative species from the Brachionus plicatilis species complex: adult females, neonates (newborns), and diapausing eggs. Scale bar $=100 \mu \mathrm{m}$. CT: Connecticut, s.s.: sensu strictu

$72 \mathrm{~h}$ varied from $100 \%$ for Bm Manjavacas to as little as $7 \%$ for B. sp. LL1 and Nev2. The reason for this large variation is not known. The mean hatching fraction of all 15 strains in the collection is $59.2 \% \pm 28.4$.

Population growth rates $(r)$

Diapausing eggs hatch into asexual females that begin reproducing within $24 \mathrm{~h}$ of hatching. Different species grow at different rates in our culture conditions
(Fig. 2). We observed population growth rates as high as $r=0.91$ for Bm GP and as low as $r=0.37$ for Bp Poza Sur. Population growth rates were determined in a common environment, so they likely reflect genetic differences among species. These species may perform differently if cultured in different environmental conditions. 
Table 4 Comparison of diapausing egg productions among Brachionus species

Diapausing egg density is the mg dry weight of diapausing eggs produced per liter of culture. $29 \%$ of strains tested did not produce any diapausing eggs (7 out of 24)

Bm: Brachionus manjavacas; $\mathrm{Bp}$ :

Brachionus plicatilis; $\mathrm{Br}$ : Brachionus rotundiformis; Bc: Brachionus calyciflorus; RUS: Russian; Petta: Pettaquamscutt; MAN: Manjavacas; SAL: Salobrejo; HAW: Hawaii; JPN: Japan; Nev2: Nevada 2; LL1: Lost Lake 1; GP: Gaynor Pond

\begin{tabular}{|c|c|c|c|c|}
\hline Strain & \# Bags & Diapausing eggs $(g)$ & Diapausing egg density (mg/l) & Date \\
\hline B sp. LL1 & 10 & 0.3 & 2.50 & May-17 \\
\hline B sp. LL1 & 5 & 0.4 & 6.67 & Aug-17 \\
\hline Br Italy & 10 & 0.4 & 3.33 & Jun-17 \\
\hline Br Italy & 10 & 0.9 & 7.50 & Jul-17 \\
\hline Bp AUYEN020 & 4 & 0.4 & 8.33 & Aug-17 \\
\hline Bp Poza Sur & 5 & 0.4 & 6.67 & Sep-17 \\
\hline Bp China & 5 & 0.9 & 15.00 & Sep-17 \\
\hline Bp Tokyo & 5 & 1.0 & 16.67 & Sep-17 \\
\hline B sp. Nev2 & 5 & 1.0 & 16.67 & Oct-17 \\
\hline Bm Petta2002 & 5 & 0.8 & 13.33 & Oct-17 \\
\hline Bm Petta2003 & 5 & 0.4 & 6.67 & Oct-17 \\
\hline B sp. JPN S-type & 10 & 1.9 & 15.83 & Dec-17 \\
\hline Bp AUPEA006 & 5 & 1.3 & 21.67 & Jan-18 \\
\hline Bm MAN & 5 & 1.1 & 18.33 & Jan-18 \\
\hline Bm GP & 5 & 0.3 & 5.00 & Feb-18 \\
\hline Bm RUS & 5 & 0.5 & 8.33 & Feb-18 \\
\hline Bp SAL & 5 & 0.7 & 11.67 & Apr-18 \\
\hline Br HAW & 5 & 2.4 & 40.0 & Apr-18 \\
\hline Bc Gainesville & 5 & 0.7 & 7.27 & May-18 \\
\hline \multirow[t]{3}{*}{ Bc Piedmont } & 1 & 0.05 & 4.0 & Apr 18 \\
\hline & & Mean & 11.69 & \\
\hline & & SD & 2.62 & \\
\hline
\end{tabular}

\section{Discussion}

Rotifer diapausing eggs are the products of sexual reproduction and are diapausing embryos highly resistant to desiccation, high temperatures, salinities, and UV exposure (Schroder, 2005). They are produced in natural populations as a means of escaping environments unsuitable for rotifer growth (Tarazona et al., 2017). Diapausing eggs are released by females, fall to the bottom, and are buried in the sediments, where they can remain dormant for decades (GarcíaRoger et al., 2006). Diapausing eggs can be produced in the laboratory under controlled conditions, collected, dried, and provided to aquaculturists for use in larval rearing operations (Hagiwara et al., 1997; Balompapueng et al., 1997a). These authors described techniques for producing diapausing eggs for one strain each of Brachionus plicatilis and B. rotundiformis. Our work extends to 16 the number of Brachionus species for which diapausing eggs can be produced for aquaculture. In addition, there are some locations where natural production of rotifer diapausing eggs can be collected and used in aquaculture (Dhert et al., 1997).

Rotifers are produced in most hatcheries in batch or semicontinuous cultures that are fed live or preserved microalgae (Hagiwara et al., 2007, 2017). The intent of hatchery managers is to maximize the production of rotifer biomass/l in large, open tanks. A variety of bacteria, fungi and ciliates typically colonize these tanks, the composition of which is uncontrolled. Sooner or later undesirable contaminants colonize the tanks, and rotifer production declines. As a result, tanks need to be drained, cleaned, and re-started to restore production levels. It is critical that the rotifer inoculant for this upscaling be free from contaminants so that new populations can achieve maximum growth rates. Rotifers obtained by hatching diapausing eggs are contaminant-free and hatch into females that begin rapid asexual reproduction. Our experience has been that most contaminant problems and mass culture crashes can be avoided if rotifer cultures are periodically renewed from diapausing egg inocula. Doing this once every 3 months is usually sufficient to avoid problems. 
Table 5 Comparison of diapausing egg hatching productions among Brachionus species

\begin{tabular}{llrrr}
\hline Strain & Salinity psu & \multicolumn{3}{l}{$\begin{array}{l}\text { Cumulative percent } \\
\text { hatching }\end{array}$} \\
\cline { 2 - 5 } & \multicolumn{5}{c}{$24 \mathrm{~h}$} & $48 \mathrm{~h}$ & $72 \mathrm{~h}$ \\
\hline Bm RUS & 15 & 45.0 & 59.0 & 61.0 \\
Bm Petta & 15 & 66.0 & 75.0 & 77.0 \\
Bm MAN & 7.5 & 84.0 & 98.3 & 100.0 \\
Bm GP & 7.5 & 50.0 & 73.3 & 77.5 \\
Bp Poza Sur & 7.5 & 5.0 & 55.8 & 55.8 \\
Bp China & 7.5 & 70.0 & 98.3 & 99.2 \\
Bp Tokyo & 15 & 4.2 & 61.7 & 70.0 \\
Bp SAL & 15 & 5.0 & 48.3 & 55.8 \\
Bp AUPEA006 & 7.5 & 0.8 & 10.0 & 25.8 \\
Br Italy & 15 & 0.0 & 48.9 & 67.0 \\
B sp. JPN S-type & 7.5 & 22.5 & 38.3 & 42.5 \\
B sp. Nev2 & 15 & 0.0 & 5.8 & 7.5 \\
B sp. LL1 & 15 & 2.0 & 6.0 & 7.0 \\
Br HAW & 27 & 0.0 & 62.5 & 65.0 \\
Bc Gainesville & 0 & 70.0 & 75.8 & 77.5 \\
\hline Bm. Brachionus & & &
\end{tabular}

Bm: Brachionus manjavacas; Bp: Brachionus plicatilis; $\mathrm{Br}$ : Brachionus rotundiformis; Bc: Brachionus calyciflorus; RUS: Russian; Petta: Pettaquamscutt; MAN: Manjavacas; SAL: Salobrejo; HAW: Hawaii; JPN: Japan; Nev2: Nevada 2; LL1: Lost Lake 1; GP: Gaynor Pond
To initiate rotifer cultures from diapausing egg inocula, a 1-100 1 culture of live microalgae is grown to a density of about $10^{5}-10^{6}$ cells $/ \mathrm{ml}$. Many algae species are suitable, including Tetraselmis, Nannochloropsis, Chlorella, Isochrysis, and Dunaliella, grown at temperatures of $15-32^{\circ} \mathrm{C}$ and salinities of 15-35 psu. Approximately 100 rotifer diapausing eggs/l are introduced into the algae culture where they hatch in about $24 \mathrm{~h}$. Diapausing egg hatchlings initiate rapid asexual reproduction and soon enter into log phase population growth. It is possible to completely sterilize the rotifer diapausing eggs by decapsulating them with chlorine bleach (Snell et al., 2010) or treating them with other disinfectants (Balompapueng et al., 1997b). After about 1 week, depending on temperature, the culture will contain a dense population of rotifers, free of contaminants, that is suitable for inoculating mass culture production tanks. The speed of this upscaling enables hatchery managers to grow rotifer mass cultures only when needed (Snell \& Hoff, 1988). Otherwise, rotifer stocks can remain dormant in a freezer, requiring no maintenance and with no risk of contamination.

Periodically using rotifer diapausing egg inocula enables aquaculturists to maintain tight control over the genetic composition of their rotifer species. Mass cultures close to the sea are especially prone to

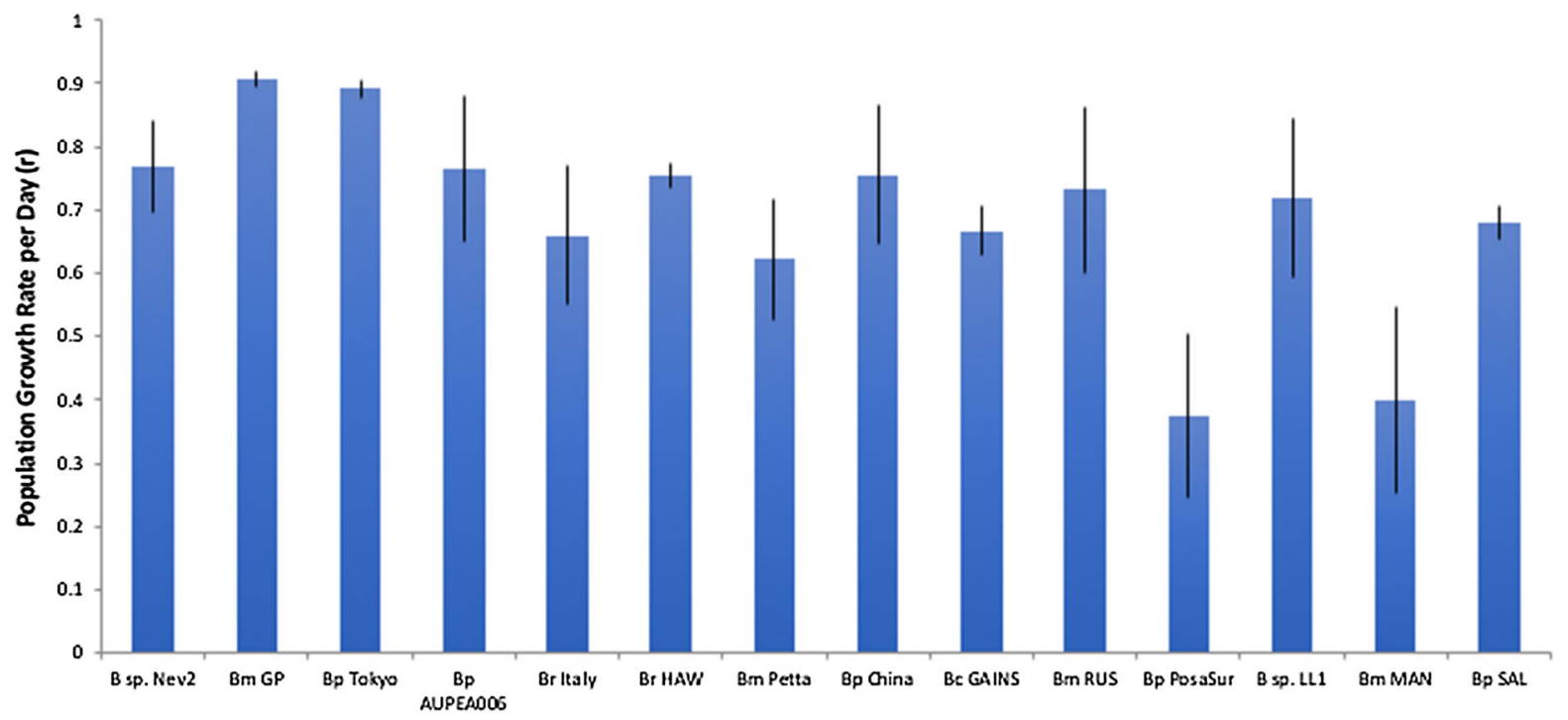

Fig. 2 Comparative 3-day asexual population growth rate estimates for several B. plicatilis species. For species definitions, see Table 1. Bm: Brachionus manjavacas; Bp: Brachionus plicatilis; Br: Brachionus rotundiformis; Nev2: Nevada
2; GP: Gaynor Pond; HAW: Hawaii; Petta: Pettaquamscutt; GAINS: Gainesville; RUS: Russian, LL1: Lost Lake 1; MAN: Manjavacas; SAL: Salobrejo 
colonization by wild zooplankton. Even the best tank management practices cannot keep species propagated by serial dilution free of contamination through years of culture. This can lead to shifts in rotifer body size as one species replaces another in mass culture tanks (Kotani, 2017). Our experience has been that small rotifer species are particularly vulnerable to invasion and replacement by larger species. Returning to reliable diapausing egg inocula periodically insures that the best rotifer species is provided to larval predators.

There are well-established methods for conserving genetic stocks of rotifers used in aquaculture. When a new rotifer species or strain is collected from a natural population, rotifer scientists often clone the population immediately. Starting a population from a single parthenogenetic female drastically reduces the genetic variability of the population. This clone also may have a low propensity for sex (Franch-Gras et al., 2017), making diapausing egg production in laboratory difficult. Working with rotifer clones lacking sexual reproduction may be desirable for scientific investigations, but it is not ideal for aquaculture. A better approach for maintaining a population's genetic diversity and capacity for diapausing egg production is to collect sediments from habitats of known Brachionus populations. The natural habitats of all of these B. plicatilis species are inland salt lakes or coastal marine environments. These sediments usually contain a sample of diapausing eggs from the diapausing egg bank that has accumulated over decades of rotifer growth at the site (Montero-Pau et al., 2017). Initiating a rotifer population from diapausing eggs hatched from sediments will enable aquaculturists to begin their cultures with genetically diverse rotifer populations still able to produce diapausing eggs. It is preferable to preserve a rotifer strain as diapausing eggs before it loses its ability for sexual reproduction. Loss of sex can happen quickly because the culture practices of most laboratories selects against diapausing egg production (Serra \& Snell, 2009). Although it is convenient to initiate rotifer mass cultures from live samples obtained from other hatcheries, the risk of introducing unwanted contaminants into rotifer cultures is high. Moreover, using rotifers from other hatcheries may not provide the best species for local growing conditions or the larval predator being cultivated. It is best to systematically test the full range of Brachionus biodiversity available to determine which strain is optimal for a particular hatchery site and season and larval predator.

As the result of many years of intensive research, methods have been developed to produce diapausing eggs of several $B$. plicatilis complex species in the laboratory. As a result of this work, diapausing eggs from several geographic isolates of five species now are available to the aquaculture industry for testing in commercial hatcheries. These include Brachionus plicatilis s.s. (mean adult body length: $261 \mu \mathrm{m}$, Muller, 1786), B. manjavacas (mean body length: $247 \mu \mathrm{m}$, Fontaneto et al., 2007), B. rotundiformis (mean body length: $148 \mu \mathrm{m}$, Segers, 1995), and $B$. sp. Nevada (mean body length: $191 \mu \mathrm{m}$, Mills et al., 2017), B. sp. Almenara (mean body length: $162 \mu \mathrm{m}$, Mills et al., 2017). These 5 species represent only about $1 / 3$ of the global biodiversity in the B. plicatilis species complex. At least 10 more $B$. plicatilis complex species exist, many unnamed, each with unique properties of size, optimal growth conditions, and diet. These include: B. ibericus (Ciros-Perez et al., 2001), B. koreanus (Hwang et al., 2013), and $B$. asplanchnoidis (Michaloudi et al., 2017), but diapausing eggs are not yet available for these species.

The Brachionus body sizes that we report in Table 3 are consistent with those reported by Suatoni et al. (2006). For example, the mean length for $\mathrm{L}$ clades reported by Suatoni et al. is $281 \mu \mathrm{m}$ and similar to the means of $261 \mu \mathrm{m}$ for our B. plicatilis species and $247 \mu \mathrm{m}$ for B. manjavacas (L clades). Suatoni et al. report an $\mathrm{S}$ clade mean length of $144 \mu \mathrm{m}$ for their populations, and we report a mean length of $148 \mu \mathrm{m}$ for our B. rotundiformis species. In contrast, our results are quite distinct from Campillo et al. (2005), who report a mean length for B. plicatilis of $386 \mu \mathrm{m}$ and B. manjavacas of $361 \mu \mathrm{m}$. Interestingly, Campillo et al. report that their B. manjavacas is $6 \%$ smaller than their B. plicatilis, just as we observed.

In 2009, a new marine rotifer was introduced to aquaculture called Proales similis (Wullur et al., 2009). At $83 \mu \mathrm{m}$ long and $40 \mu \mathrm{m}$ wide, it is considerably smaller than even the smallest Brachionus rotundiformis. Proales has been mass cultured and demonstrated to be good food for seven-banded grouper larvae (Wullur et al., 2011). The potential of this rotifer species for marine finfish larviculture is currently being explored. To facilitate these activities, diapausing eggs from this species have been produced 
in our laboratory and now are available to commercial hatcheries for experimentation.

Most hatcheries attempt to maximize asexual reproduction in their rotifer cultures to avoid the cost of producing males, and its concomitant reduction in population growth rate (Serra et al., 2004). Under the serial dilution culture regimes of most mass cultures, sex is typically rapidly lost in a few dozen generations (months). Sex also can be suppressed by promoting culture conditions like high population densities $(>100 / \mathrm{ml})$, high temperatures $\left(>30^{\circ} \mathrm{C}\right)$, high salinities ( $>35 \mathrm{psu}$ ), or limited food. Considering these observations, sexual reproduction in mass cultures should only be a transient hindrance for rotifer production, easily manipulated by culture conditions.

The nutritional quality of rotifers is another major concern for hatchery managers. All of the rotifer species that are available as diapausing eggs eat a similar microalgae diet. This includes live algae like Tetraselmis, Nannochloropsis, Chlorella, Isochrysis, and Dunaliella, refrigerated algae paste, or dried algae products like S.parkle, Algamac (Aquafauna), ORIOne (Skretting), or Nutrispring (Nannochloropsis gaditana lyophilized powder, AlgaSpring). It is more reliable to start diapausing egg hatchlings with live algae because inoculation density typically is quite low $(\sim 100$ rotifers/l) and a live algae diet gives rotifers the best chance to become the dominant grazers in mass cultures. As rotifer populations grow to higher densities, many preserved algal products become suitable as supplemental feeds to expand and sustain mass cultures. All rotifer species exhibit good growth on these diets, but because diet likely interacts with environmental conditions, each rotifer species will require optimization to the specific conditions of the hatchery.

Acknowledgements We express our appreciation for the technical assistance provided by Nancy Park and Jamie Rogers. We also are grateful to several rotifer researchers who supplied rotifer samples over the years, including A. Hagiwara, M. Serra, L. Suatoni, S. Nandini, P. Sorgeloos, and S. Hampton. Matthew Carberry, Sustainable Aquatics (http:// sustainableaquatics.com) provided useful discussion that improved this paper. This work was supported in part by the Georgia Tech School of Biological Sciences and the Elizabeth Smithgall Watts endowment.

Open Access This article is distributed under the terms of the Creative Commons Attribution 4.0 International License (http:// creativecommons.org/licenses/by/4.0/), which permits unrestricted use, distribution, and reproduction in any medium, provided you give appropriate credit to the original author(s) and the source, provide a link to the Creative Commons license, and indicate if changes were made.

\section{References}

Balompapueng, D. M., A. Hagiwara, Y. Nozaki \& K. Hirayama, 1997a. Preservation of resting eggs of the euryhaline rotifer Brachionus plicatilis O. F. Müller by canning. Hydrobiologia 358: 163-166.

Balompapueng, M. D., N. Munuswamy, A. Hagiwara \& K. Hirayama, 1997b. Effect of disinfectants on the hatching of marine rotifer resting eggs Brachionus plicatilis Muller. Aquaculture Research 28: 559-565.

Campillo, S., E. M. Garcia-Roger, D. Martınez-Torres \& M. Serra, 2005. Morphological stasis of two species belonging to the L-morphotype in the Brachionus plicatilis species complex. Hydrobiologia 546: 181-187.

Ciros-Perez, J., A. Gomez \& M. Serra, 2001. On the taxonomy of three sympatric sibling species of the Brachionus plicatilis (Rotifera) complex from Spain, with the description of B. ibericus n. sp. Journal of Plankton Research 23: 1311-1328.

Conceicao, L. E. C., M. Yufera, P. Makridis, S. Morais \& M. T. Dinis, 2010. Live feeds for early stages of fish rearing. Aquaculture Research 41: 613-640.

Dhert, P., K. Schoeters, P. Vermeulen, J. Sun, S. Gao, Z. Shang, X. Naihong, H. Van Duffel \& P. Sorgeloos, 1997. Production, disinfection and evaluation for aquaculture applications of rotifer resting eggs from Bohai Bay, P.R. of China. Aquaculture International 5: 105-112.

Fontaneto, D., I. Giordani, G. Melone \& M. Serra, 2007. Disentangling the morphological stasis in two rotifer species of the Brachionus plicatilis species complex. Hydrobiologia 583: 297-307.

Franch-Gras, L., E. M. Garcia-Roger, M. Serra \& M. J. Carmona, 2017. Adaptation in response to environmental unpredictability. Proceedings of the Royal Society B 284: 20170427.

Fu, Y., K. Hirayama \& Y. Natsukari, 1991. Morphological differences between two types of the rotifer Brachionus plicatilis O. F. Muller. Journal of Experimental Marine Biology and Ecology 151: 29-41.

Gabaldon, C., D. Fontaneto, M. J. Carmona, J. Montero-Pau \& M. Serra, 2017. Ecological differentiation in cryptic rotifer species: what we can learn from the Brachionus plicatilis complex. Hydrobiologia 796: 7-18.

García-Roger, E. M., M. J. Carmona \& M. Serra, 2006. Patterns in rotifer diapausing egg banks: density and viability. Journal of Experimental Marine Biology and Ecology 336: 198-210.

Guillard, R. R. L., 1983. Culture of phytoplankton for feeding marine invertebrates. In: Berg Jr., C. J. (ed), Culture of Marine Invertebrates Hutchinson Ross, Stroudsburg, PA.

Hagiwara, A., M. D. Balompapueng, N. Munuswamy \& K. Hirayama, 1997. Mass production and preservation of the resting eggs of the euryhaline rotifer Brachionus plicatilis and B. rotundiformis. Aquaculture 155: 223-230. 
Hagiwara, A., W. G. Gallardo, M. Assavaaree, T. Kotani \& A. B. de Araujo, 2001. Live food production in Japan: recent progress and future aspects. Aquaculture 200: 111-127.

Hagiwara, A., K. Suga, A. Akazawa, T. Kotani \& Y. Sakakura, 2007. Development of rotifer strains with useful traits for rearing fish larvae. Aquaculture 268: 44-52.

Hagiwara, A., H. J. Kim \& H. Marcial, 2017. Mass culture and preservation of Brachionus plicatilis sp. complex. In Hagiwara, A. \& T. Yoshinaga (eds), Rotifers, Fisheries Science Series. Springer Nature Singapore Pte Ltd, Singapore: $35-46$.

Hwang, D. S., H. U. Dahms, H. G. Park \& J. S. Lee, 2013. A new intertidal Brachionus and intrageneric phylogenetic relationships among Brachionus as revealed by allometry and CO1-ITS1 gene analysis. Zoological Studies 52: 1-10.

Kim, H. J., M. Iwabuchi, Y. Sakakura \& A. Hagiwara, 2017. Comparison of low temperature adaptation ability in three native and two hybrid strains of the rotifer Brachionus plicatilis species complex. Fisheries Science 83: 65-72.

Kostopoulou, V., H. Miliou \& G. Verriopoulos, 2009. Morphometric changes in a strain of the lineage 'Nevada', belonging to the Brachionus plicatilis (Rotifera) complex. Aquaculture Research 40: 938-949.

Kotani, T., 2017. The current status of the morphological classification of rotifer strains used in aquaculture. In Hagiwara, A. \& T. Yoshinaga (eds), Rotifers, Fisheries Science Series. Springer Nature Singapore Pte Ltd., Singapore: 3-14.

Kotani, T., K. Ihara \& A. Hagiwara, 2006. Cross-mating of euryhaline rotifer Brachionus plicatilis strains as a means to develop useful strains for larval fish food. Aquaculture 261: 495-500.

Lubzens, E., O. Zmora \& Y. Barr, 2001. Biotechnology and aquaculture of rotifers. Hydrobiologia 446(447): 337-353.

Michaloudi, E., S. Mills, S. Papakostas, C. P. Stelzer, A. Triantafyllidis, I. Kappas, K. Vasileiadou, K. Proios \& T. J. Abatzopoulos, 2017. Morphological and taxonomic demarcation of Brachionus asplanchnoidis Charin within the Brachionus plicatilis cryptic species complex (Rotifera, Monogononta). Hydrobiologia 796: 19-37.

Mills, S., J. A. Alcantara-Rodriguez, J. Ciros-Perez, A. Gomez, A. Hagiwara, K. H. Galindo, C. D. Jersabek, R. Malekzadeh-Viayeh, F. Leasi, J. S. Lee, D. B. Mark Welch, S. Papakostas, S. Riss, H. Segers, M. Serra, R. Shiel, R. Smolak, T. W. Snell, C. P. Stelzer, C. Q. Tang, R. L. Wallace, D. Fontaneto \& E. J. Walsh, 2017. Fifteen species in one: deciphering the Brachionus plicatilis species complex (Rotifera, Monogononta) through DNA taxonomy. Hydrobiologia 796: 39-58.

Montero-Pau, J., M. Serra \& A. Gomez, 2017. Diapausing egg banks, lake size, and genetic diversity in the rotifer Brachionus plicatilis Muller (Rotifera, Monogononta). Hydrobiologia 796: 77-91.

Muller, O. F., 1786. Animacula infusoria fluviatilia et marina, quae detexit, systematice descripsit et ad vivum delineari curavit. Havniae [Copenhagen] et Lipsiae [Leipzig]: cura Othonis Fabricii, typis Nicolai Molleri.

Ortells, R., A. Gomez \& M. Serra, 2003. Coexistence of cryptic rotifer species: ecological and genetic characterisation of Brachionus plicatilis. Freshwater Biology 48: 2194-2202.

Papakostas, S., S. Dooms, A. Triantafyllidis, D. Deloof, I. Kappas, K. Dierckens, T. DeWolf, P. Bossier, O. Vadstein,
S. Kui, P. Sorgeloos \& T. J. Abatzopoulos, 2006. Evaluation of DNA methodologies in identifying Brachionus species used in European hatcheries. Aquaculture 255: 557-564.

Pourriot, R. \& T. W. Snell, 1983. Resting eggs of rotifers. Hydrobiologia 104: 213-224.

Schroder, T., 2005. Diapause in monogonont rotifers. Hydrobiologia 546: 291-306.

Segers, H., 1995. Nomenclatural consequences of some recent studies on Brachionus plicatilis (Rotifera, Brachionidae). Hydrobiologia 313(314): 121-122.

Serra, M. \& D. Fontaneto, 2017. Speciation in the Brachionus plicatilis species complex. In Hagiwara, A. \& T. Yoshinaga (eds), Rotifers, Fisheries Science Series. Springer Nature Singapore Pte Ltd., Singapore: 14-32.

Serra, M. \& T. W. Snell, 2009. Sex loss in rotifers. In Martens, K., I. Schön \& P. van Dijk (eds), Lost Sex: The Evolutionary Biology of Parthenogenesis. Springer, Berlin.

Serra, M., T. W. Snell \& C. E. King, 2004. The timing of sex in monogonont rotifers. In Moya, A. \& E. Font (eds), Evolution: From Molecules to Ecosystems. Oxford University Press, Oxford: 135-146.

Snell, T. W. \& K. Carrillo, 1984. Body size variation among strains of the rotifer Brachionus plicatilis. Aquaculture 37: 359-367.

Snell, T. W. \& F. H. Hoff, 1988. Recent advances in rotifer culture. Aquaculture Magazine 9(10): 41-45.

Snell, T. W., T. L. Shearer \& H. A. Smith, 2010. Exposure to dsRNA elicits RNA interference in Brachionus manjavacas (Rotifera). Marine Biotechnology. https://doi.org/10. 1007/s10126-010-9295-x.

Suatoni, E., S. Vicario, S. Rice, T. Snell \& A. Caccone, 2006. An analysis of species boundaries and biogeographic patterns in a cryptic species complex: the rotifer-Brachionus plicatilis. Molecular Phylogenetics and Evolution 41: 86-98.

Tarazona, E., E. M. García-Roger \& M. J. Carmona, 2017. Experimental evolution of bet hedging in rotifer diapause traits as a response to environmental unpredictability. Oikos 126: 1162-1172.

United States Environmental Protection Agency. 1985. Methods for Measuring the Acute Toxicity of Effluents to Freshwater and Marine Organisms. EPA/600/4-85/013. USEPA.

Walczynska, A. \& M. Serra, 2014. Inter- and intraspecific relationships between performance and temperature in a cryptic species complex of the rotifer Brachionus plicatilis. Hydrobiologia 734: 17-26.

Walsh, E. J., L. May \& R. L. Wallace, 2017. A metadata approach to documenting sex in phylum Rotifera: diapausing embryos, males, and hatchlings from sediments. Hydrobiologia 796: 265-276.

Wullur, S., Y. Sakakura \& A. Hagiwara, 2009. The minute monogonont rotifer Proales similis de Beauchamp: Culture and feeding to small mouth marine fish larvae. Aquaculture 293: 62-67.

Wullur, S., Y. Sakakura \& A. Hagiwara, 2011. Application of the minute monogonont rotifer Proales similis de Beauchamp in larval rearing of seven-band grouper Epinephelus septemfasciatus. Aquaculture 313: 355-360.

Yufera, M., 1982. Morphometric characterization of a smallsized strain of Brachionus plicatilis in culture. Aquaculture 27: 55-61. 